\title{
Transformation mechanism of magnetite nanoparticles
}

\author{
Umar SAeEd Khan ${ }^{1 *}$, Amanullah ${ }^{1}$, Abdul Manan ${ }^{1}$, NASrullah Khan ${ }^{2}$, \\ AMIR MAHMOOD ${ }^{1}$, ABDUR RAHIM $^{3}$ \\ ${ }^{1}$ Department of Physics, University of Science and Technology Bannu, Pakistan \\ ${ }^{2}$ Department of Physics, Kohat University of Science and Technology, Kohat, Pakistan \\ ${ }^{3}$ Interdisciplinary Research Centre in Biomedical Materials (IRCBM), COMSATS Institute of Information Technology, \\ Lahore, Pakistan
}

\begin{abstract}
A simple oxidation synthesis route was developed for producing magnetite nanoparticles with controlled size and morphology. Investigation of oxidation process of the produced magnetite nanoparticles (NP) was performed after synthesis under different temperatures. The phase transformation of synthetic magnetite nanoparticles into maghemite and, henceforth, to hematite nanoparticles at different temperatures under dry oxidation has been studied. The natural magnetite particles were directly transformed to hematite particles at comparatively lower temperature, thus, maghemite phase was bypassed. The phase structures, morphologies and particle sizes of the produced magnetic nanoparticles have been investigated by X-ray diffraction (XRD), transmission electron microscopy (TEM), energy dispersive X-ray spectrometry (EDX) and BET surface area analysis.
\end{abstract}

Keywords: transformation; magnetite; maghemite; hematite; nanoparticles

(C) Wroclaw University of Technology.

\section{Introduction}

Iron oxides (IO), such as magnetite, maghemite and hematite nanoparticles (NP), have attracted great attention in the recent years, because of their technological and industrial applications due to their excellent and unique properties [1-7]. Iron oxides are metal oxides used in such fields as high density magnetic recording media, gas sensors, catalysts, pigments, nonlinear optics, anticorrosive agents, inorganic dyes, adsorbents, electronics, magnetic storage, biomedicine, ferrofluids and so on [8-10]. Iron oxides are common compounds that exist as natural minerals and can also be produced artificially. The IO polymorphic nature has been known for a long time. Nowadays, IO and iron hydroxides exist in sixteen types. Some iron oxides contain iron(II) and the others contain iron(III), but magnetite, having a unique nature, contains both iron(II) and iron(III) in its structure [9, 10]. Thermodynamically it is not stable in aerobic atmosphere. The oxidation rate of natural magnetite, i.e.

*E-mail: omar_aps@yahoo.co.uk bulk magnetite in an aerobic atmosphere is very slow, so no protection against oxidation is required. On the other hand, synthetic magnetites NP are either oxidized to other iron oxides during the synthesis process or during storage in ambient atmosphere [8]. Maghemite can be considered as an entirely oxidized magnetite: the intermediate form of hematite and magnetite. It is metastable with respect to hematite, which is a stable and common phase of IO [11].

In this paper we present preparation of magnetite nanoparticles by a modified oxidation method and, henceforth, transformation of the prepared samples into maghemite and hematite nanoparticles performed through dry oxidation process in ambient atmosphere. The transformation of bulk magnetite to maghemite and hematite through dry oxidation under atmospheric conditions has been proven in $[12,13]$. However, a comprehensive study of the possible transformations of the magnetite NP to other phases of IO with respect to particle size, surface area and shape has not been discussed in details so far. 


\section{Materials and methods}

Magnetite NP were produced by modified oxidation route. $20.00 \mathrm{~g}$ of $\mathrm{FeCl}_{2} \cdot 4 \mathrm{H}_{2} \mathrm{O}$ was dissolved in $140 \mathrm{~mL}$ deoxygenated deionized water. $6.46 \mathrm{~g}$ of $\mathrm{KNO}_{3}$ and $11.22 \mathrm{~g}$ of $\mathrm{NaOH}$ were dissolved in $60 \mathrm{~mL}$ deoxygenated water. The mixed solution of $\mathrm{KNO}_{3}$ and $\mathrm{NaOH}$ was dropped into the iron solution at the rate of $1 \mathrm{~mL} / \mathrm{s}$ until the temperature of the iron solution achieved 40 or $80^{\circ} \mathrm{C}$, then the system was stirred for 20 hours at that temperature. The product obtained at $40{ }^{\circ} \mathrm{C}$ was divided into three parts. Two parts of the product were heated in the furnace at 350 and $600{ }^{\circ} \mathrm{C}$. The product obtained at $80{ }^{\circ} \mathrm{C}$ was also divided into three parts. Two parts were also heated in the furnace at 400 and $800{ }^{\circ} \mathrm{C}$. Detailed information about the prepared samples has been included in Table 1 .

\section{Analytical techniques}

The prepared samples were characterized for phase composition and crystallinity with the help of XRD (Rigaku RAD-B system) at a scanning rate of $3 \% \mathrm{~min}$, employing $\mathrm{CuK} \alpha$ radiation $(\lambda=0.15405 \mathrm{~nm})$. The morphology, particles size and their size distribution in the prepared samples were studied by TEM (JEOL Model CM12), working at $100 \mathrm{kV}$ accelerating voltage. The BET (Nova 2000, Quantachrome Instruments, Boynton Beach, USA) method was used for measuring the surface area. The particle size "d" of the prepared samples was estimated using the relation $d=6 / \rho \mathrm{A}$, with density " $\rho$ " and surface area " $A$ " of the sample. The elemental composition of the sample was analyzed by EDX (JSM-5910, JEOL).

\section{Results and discussion}

The X-ray diffractograms of samples a1 - f1 are shown in Fig. 1 and Fig. 2. The XRD results of samples a1 and d1 match well to ICDD card 190629 (synthetic magnetite), revealing that on increasing the reaction temperature from 40 to $80^{\circ} \mathrm{C}$, the sharpness of the XRD peaks increased, and as a result, the particle size also increased from 9 to $15 \mathrm{~nm}$.

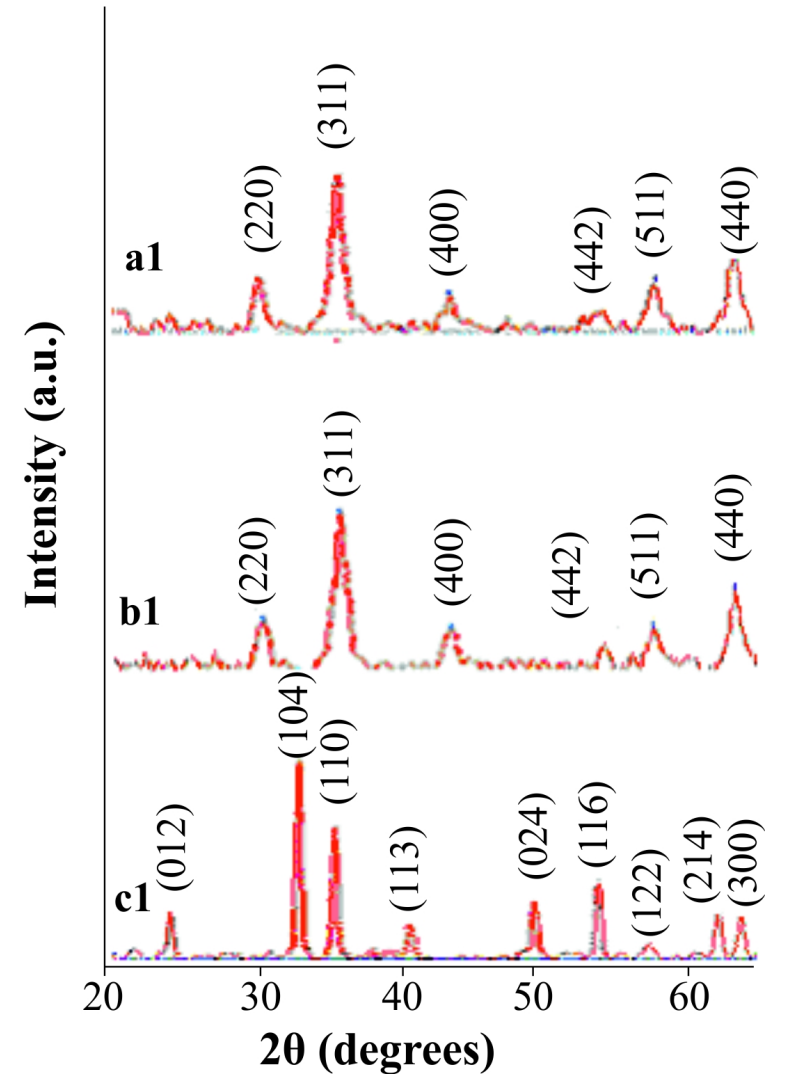

Fig. 1. XRD images of iron oxide NP produced under different conditions: (a1) $40{ }^{\circ} \mathrm{C}$ via oxidation of Iron(II) ions (magnetite), (b1) $350{ }^{\circ} \mathrm{C}$ via dry oxidation, $30 \mathrm{~min}$ (maghemite), (c1) $600{ }^{\circ} \mathrm{C}$ via dry oxidation, 60 min (hematite).

The increasing of particle size was probably due to irregular diffusion of particles at a higher temperature, which enhanced the growth kinetics of the particles and, consequently, larger sized particles were produced. Transformation of $\mathrm{Fe}(\mathrm{OH})_{2}$ to magnetite and its conversion to maghemite and hematite under different temperatures and mediums are summarized in Table 1. The XRD results for samples b1 and e1 match well to ICDD card 240081 (maghemite) and for samples c1 and f1 correspond to ICDD card 330664 (hematite). The lattice parameters of magnetite and maghemite differ slightly from each other [14]. It is illustrated in Table 2 that d-values of all the XRD peaks of maghemite samples are somewhat shifted to higher $2 \theta$ values as compared to the magnetite samples. The d-values of magnetite sample 
Table 1. Transformation of $\mathrm{Fe}(\mathrm{OH})_{2}$ to magnetite and its conversion to maghemite and hematite under different temperatures and mediums.

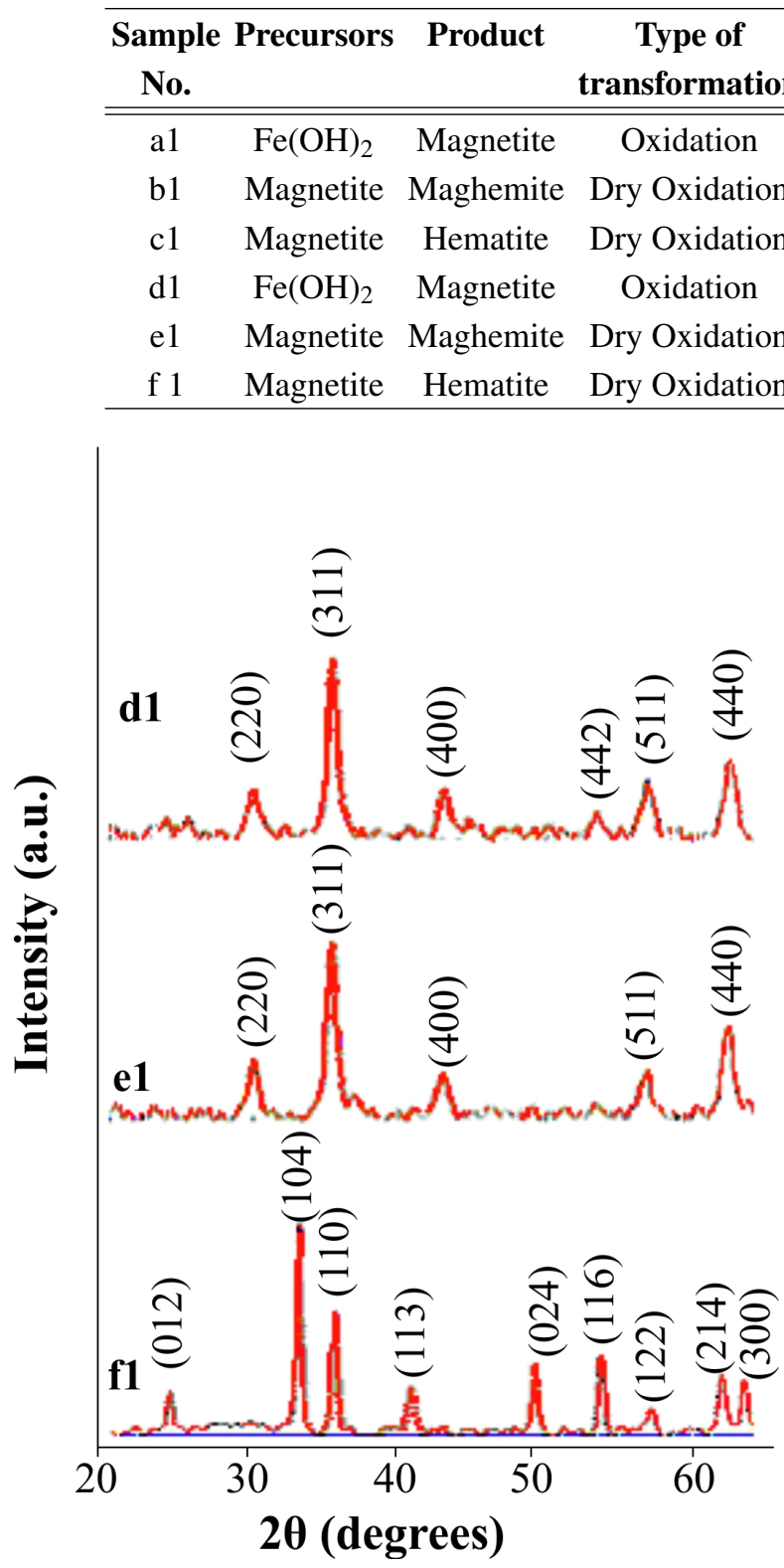

Fig. 2. XRD images of iron oxide NP produced under different conditions: (d1) $80{ }^{\circ} \mathrm{C}$ via oxidation of Iron(II) ions (magnetite), (e1) $400{ }^{\circ} \mathrm{C}$ via dry oxidation (maghemite), 30 min., (f1) $800{ }^{\circ} \mathrm{C}$ via dry oxidation (hematite), $60 \mathrm{~min}$

are slightly larger as compared to the maghemite samples.

Fig. 3 shows that X-ray diffractograms of magnetic NP prepared by oxidation route in the

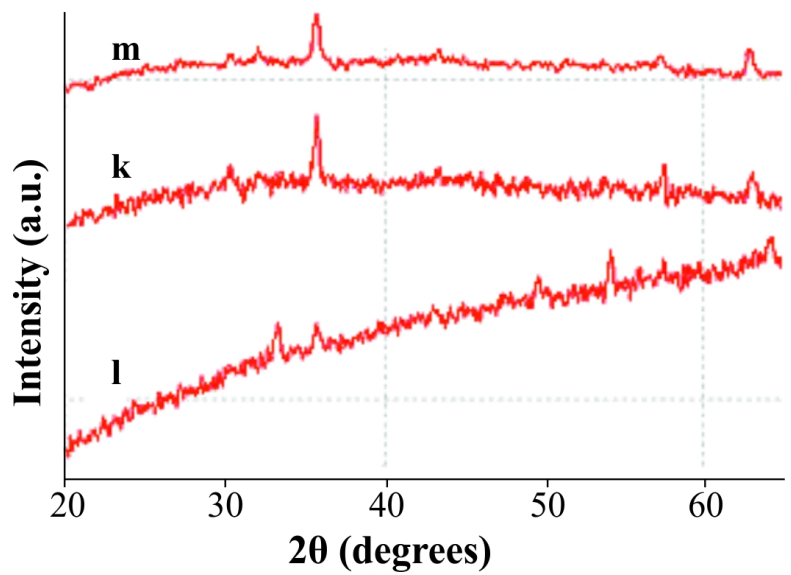

Fig. 3. XRD diffractograms of samples obtained without $\mathrm{N}_{2}$ gas protection: (m) $80{ }^{\circ} \mathrm{C}$ via oxidation of Iron(II) ions (magnetite), (k) $400{ }^{\circ} \mathrm{C}$ via dry oxidation (maghemite), $30 \mathrm{~min}$, (l) $800{ }^{\circ} \mathrm{C}$ via dry oxidation (hematite), $60 \mathrm{~min}$.

absence of $\mathrm{N}_{2}$. In this case, poorly crystalline magnetite particles were produced due to the mixing of different types of iron oxides with each others. These magnetite NP converted to poorly crystalline maghemite and hematite NP by heating magnetite $\mathrm{NP}$ in the furnace at 400 and $800{ }^{\circ} \mathrm{C}$ under dry oxidation.

Electron diffraction patterns and results of EDX analysis of samples a1, b1 and $\mathrm{c} 1$ are shown in Fig. 4. The EDX analysis of these samples shows that the prepared samples are composed of iron and oxygen only. The EDX result of sample a1 shown in Fig. 4 illustrates that the prepared sample is made of iron and oxygen. The atomic ratios in the samples shown in Fig. 4 are close to the theoretical atomic stoichiometric ratios for magnetite, 
Table 2. Comparison of $d$ values and 2 theta angles of the prepared samples of magnetite and maghemite.

\begin{tabular}{ccccccccc}
\hline \multirow{2}{*}{ (hkl) } & \multicolumn{2}{c}{ Sample a1 } & \multicolumn{2}{c}{ Sample b1 } & \multicolumn{2}{c}{ Sample d1 } & \multicolumn{2}{c}{ Sample e1 } \\
\cline { 2 - 9 } & 2 Theta & $\mathbf{d}(\AA)$ & 2 Theta & $\mathbf{d}(\AA)$ & 2 Theta & d $(\AA)$ & 2 Theta & $\mathbf{d}(\AA)$ \\
\hline \hline$(220)$ & 30.119 & 2.96469 & 30.256 & 2.95163 & 30.114 & 2.96516 & 30.156 & 2.96177 \\
$(311)$ & 35.499 & 2.52674 & 35.627 & 2.51798 & 35.495 & 2.52701 & 35.546 & 2.51851 \\
$(400)$ & 43.151 & 2.09474 & 43.379 & 2.08428 & 43.192 & 2.09288 & 43.207 & 2.09218 \\
$(511)$ & 57.094 & 1.61190 & 57.319 & 1.60611 & 57.163 & 1.61012 & 57.195 & 1.60931 \\
$(440)$ & 62.708 & 1.48041 & 62.843 & 1.47756 & 62.729 & 1.47912 & 62.862 & 1.47717 \\
\hline
\end{tabular}
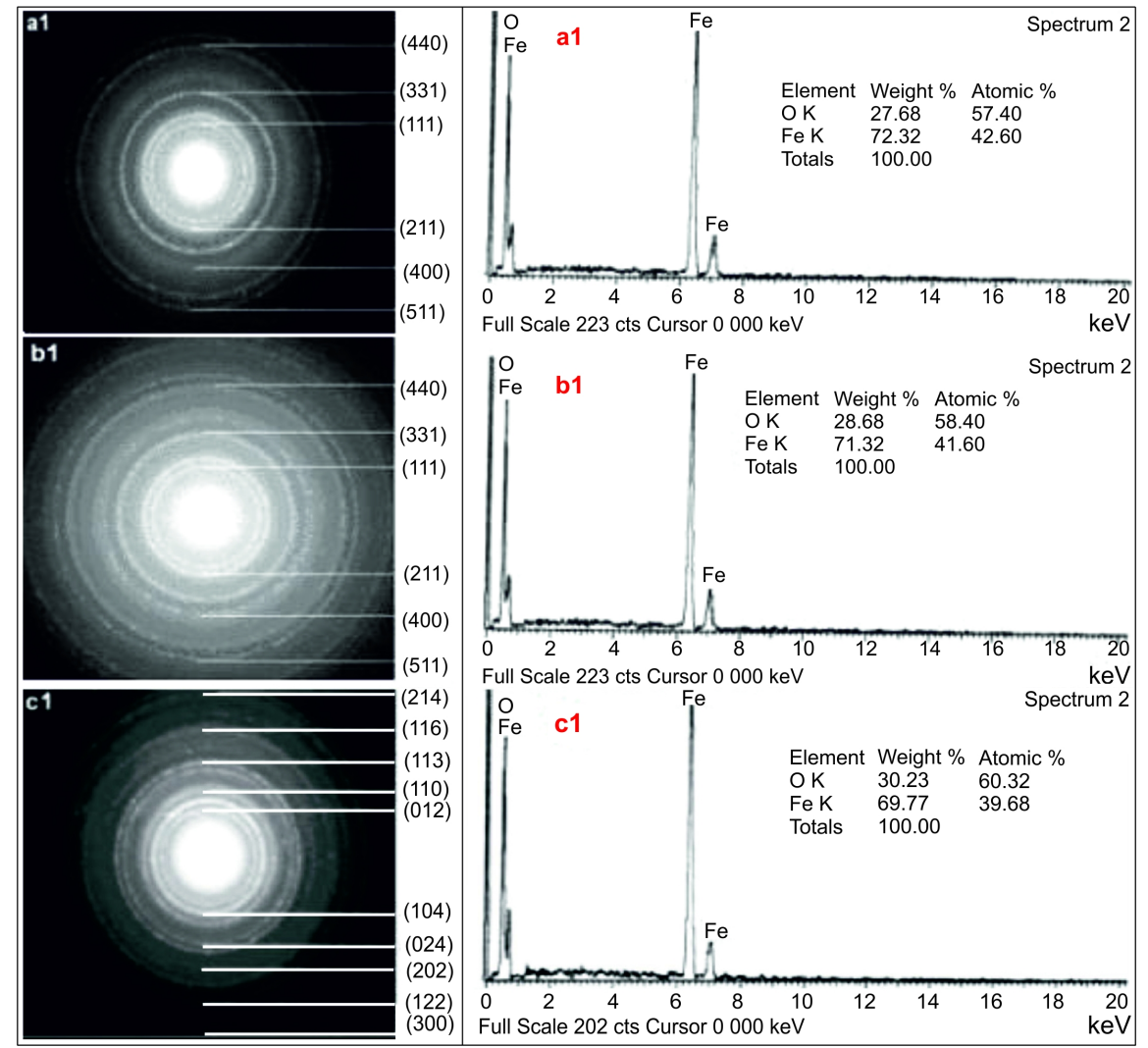

Fig. 4. Diffraction patterns and EDX images of samples a1, b1 and c1.

which are $42.9 \%$ and $57.1 \%$ for iron and oxygen, respectively. The weight ratio of the elements in sample a1, which is also shown in Fig. 4, is close to the theoretical weight stoichiometric ratio $(72.41 \%$ Fe and $27.59 \% \mathrm{O}$ ), as well. The EDX analysis shows that sample a1 consists of magnetite phase. The EDX analysis of samples b1 and c1 shows that the atomic and weight ratios of these samples, which are also shown in Fig. 4, are close to the respective theoretical atomic and weight stoichiometric ratios of maghemite and hematite. Maghemite and hematite possess the same atomic and weight ratios, however, differentiation between them can be easily made with the help of their colours. The colour of sample b1 is dark brown, which is the colour of maghemite. The colour of sample $\mathrm{c} 1$ is red, which is the colour of hematite.

The electron diffraction patterns of samples a1, b1 and $\mathrm{c} 1$ are also shown in Fig. 4. The images illustrate that the samples $\mathrm{a} 1$ and $\mathrm{b} 1$ are crystalline and have cubic spinel structures. The sample $\mathrm{c} 1$ is also crystalline and has a hexagonal structure. 
The electron diffraction patterns confirm XRD and EDX results for these samples.

TEM images of the samples, showing the shape and particle size of the produced particles, have been summarized in Table 3 and illustrated in Fig. 5. The morphology of the majority of particles contained in the samples is spherical. The particle size in the prepared samples ( $\mathrm{a} 1$ - $\mathrm{f} 1$ ) was also measured by the XRD and BET techniques the results, of which are also given in Table 3.

The transformations of magnetite to the other phases of IO via dry oxidation are shown in Table 1 . The samples a1 and $\mathrm{d} 1$ of magnetite NP (black in colour) transformed to maghemite, which is reddish brown in colour, on heating in furnace at 300 to $400{ }^{\circ} \mathrm{C}$ for $30 \mathrm{~min}$. The sample al and d1 on heating at 600 and $800{ }^{\circ} \mathrm{C}$ in furnace for $60 \mathrm{~min}$, transformed to hematite, which is dark red in colour. The results of colour variation of different phases of IO, confirmed by XRD, show that at 300 to $400{ }^{\circ} \mathrm{C}$, magnetite transformed to maghemite, which is metastable, and the heating of magnetite $\mathrm{NP}$ at 600 to $800{ }^{\circ} \mathrm{C}$, transformed it to hematite NP, the most stable phase of IO, which is the end product of this transformation process.

It was observed that magnetite transformed to maghemite at lower temperature in comparison to hematite because both magnetite and maghemite have $\mathrm{CCP}$ anion arrangement. Hematite conversion involves a change from a CCP anion arrangement to $\mathrm{HCP}$, and since substantial rearrangement of the ions is needed, a higher temperature is required for the transformation of magnetite to hematite. It was also observed that the morphology of the precursor (magnetite) was preserved throughout the transformation to maghemite and hematite, which is shown in Fig. 5. This type of transformation involves internal atomic rearrangement within a single crystal of an initial phase, which being transformed into a single crystal of another phase, undergoes so called topotactic process, which occurs within the solid phase. Solid state transformation in dry state needs certain atomic movements; it usually occurs only at the higher temperature [8].

The sizes of the samples summarized in Table 3 show that the increase in the size of maghemite
NP compared to magnetite NP, and the increase in the size of hematite NP compared to magnetite and maghemite NP, most likely involve the wellknown Ostwald ripening process [15]. Maghemite and hematite NP are produced through dry oxidation of magnetite by chain mechanism involving recrystallization of smaller particles of the precursor. The NP size is the most significant feature, which describes the nature of aerosols. The nature of aerosol particles is described by three types of forces, i.e. (i) inertial, (ii) gravitational and (iii) diffusional. The microparticle system is governed by the inertial and gravitational forces. The NP system is governed by diffusional forces and the nature of NP is more similar to a gas or a vapor, thus, it satisfies the basic laws of gaseous diffusion [16].

The magnetite NP on heating at 350 to $400{ }^{\circ} \mathrm{C}$ in air, transformed to maghemite NP via dry oxidation. This transformation mechanism agrees with diffusion phenomenon for magnetite. The transformation of magnetite to maghemite takes place by the dry oxidation of ferrous ions. The fraction transformation equation is given below [8]:

$$
M_{t} / M_{\infty}=6 \pi^{-1 / 2}\left(D t / a^{2}\right)^{1 / 2}-3 D t / a^{2}
$$

where $M_{t}$ is an iron species to be oxidized after time $t$ and $\mathrm{M}_{\infty}$ is the corresponding amount of iron after infinite time. D is the diffusion constant, which is the function of temperature and $a$ is the average radius of the particles. The diffusion is based on the particle size.

It was observed that magnetite NP smaller than $15 \mathrm{~nm}$ were readily oxidized to maghemite and hematite NP at 350 to $400{ }^{\circ} \mathrm{C}$ and 600 to $800{ }^{\circ} \mathrm{C}$ just for 30 and $60 \mathrm{~min}$ duration, respectively. It means that NP possess higher reaction rate due to the small diffusion pathways and, therefore, transform more rapidly to the other phases compared to the microparticles. The diffusion rate is slow in the larger crystal so the diffusion pathway is very long. Therefore, complete transformation of bulk magnetite to the other phases of IO needs higher temperature for a long time. The diffusion constant is inversely related to the size of NP as it is given in equation 1. It also depends on the diffusion rate during the diffusion process. The dispersion rate of 


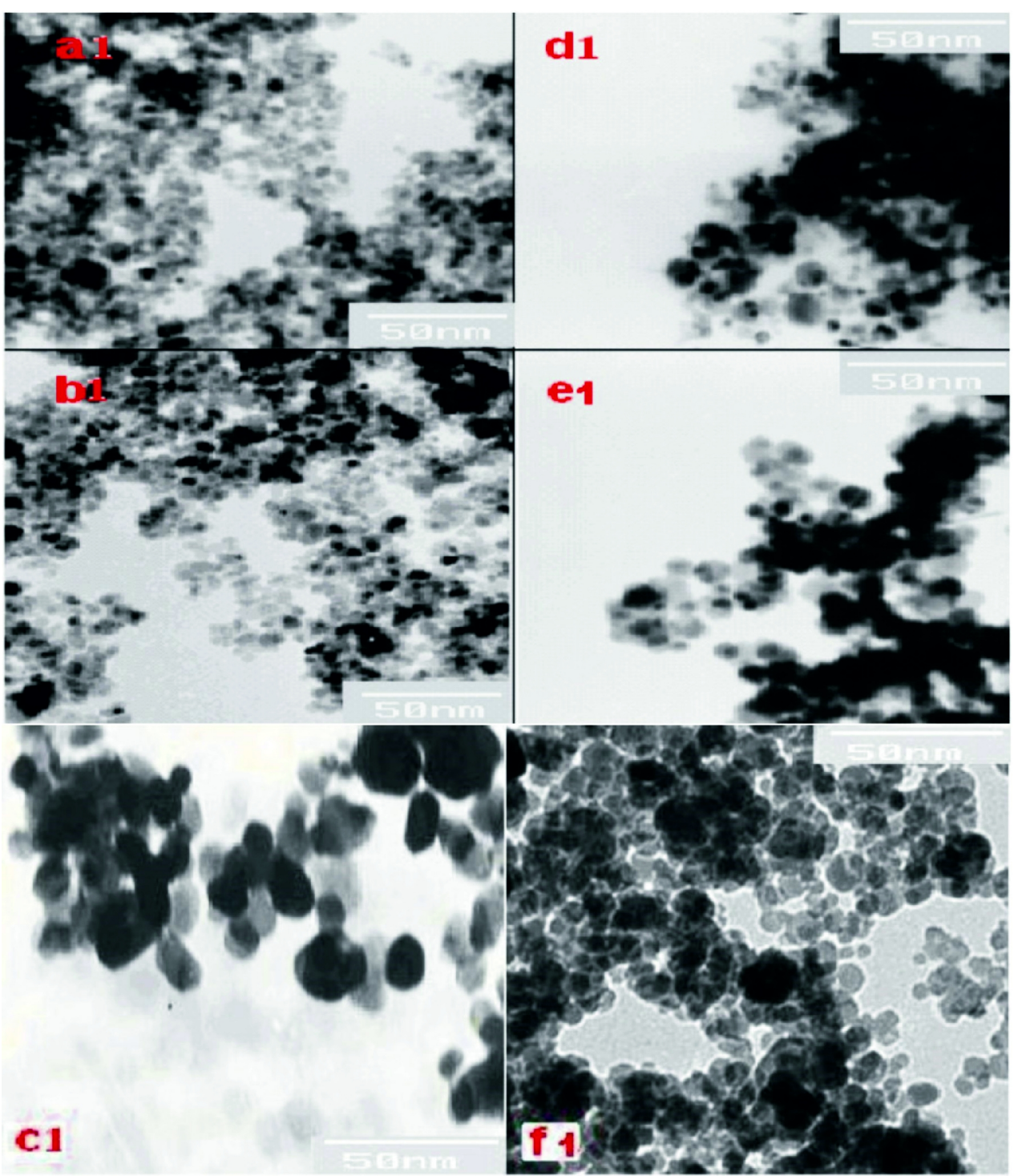

Fig. 5. TEM images of iron oxide NP produced under the following conditions:

(a1) $40{ }^{\circ} \mathrm{C}$ via oxidation of Iron(II) ions (magnetite), (b1) $350{ }^{\circ} \mathrm{C}$ via dry oxidation, 30 min (maghemite), (c1) $600{ }^{\circ} \mathrm{C}$ via dry oxidation, $60 \mathrm{~min}$ (hematite), (d1) $80{ }^{\circ} \mathrm{C}$ via oxidation of Iron(II) ions (magnetite), (e1) $400{ }^{\circ} \mathrm{C}$ via dry oxidation, $30 \mathrm{~min}$ (maghemite), and (f1) $800{ }^{\circ} \mathrm{C}$ via dry oxidation, 60 min (hematite).

Table 3. Comparison of the size of prepared particles obtained by XRD, BET and TEM.

\begin{tabular}{ccccc}
\hline Samples & $\begin{array}{c}\text { SA(BET) } \\
\left(\mathbf{m}^{2} / \mathbf{g}\right)\end{array}$ & $\begin{array}{c}\text { BET } \\
\mathbf{d}(\mathbf{n m})\end{array}$ & $\begin{array}{c}\text { XRD } \\
\mathbf{d}(\mathbf{n m})\end{array}$ & $\begin{array}{c}\text { TEM } \\
\mathbf{d}(\mathbf{n m})\end{array}$ \\
\hline \hline $\mathrm{a} 1$ & 124.70 & $9.50 \pm 0.32$ & $9.02 \pm 0.34$ & $9.66 \pm 0.66$ \\
$\mathrm{~b} 1$ & 103.50 & $11.70 \pm 0.44$ & $9.43 \pm 0.42$ & $11.38 \pm 0.71$ \\
$\mathrm{c} 1$ & 35.60 & $31.44 \pm 0.54$ & $22.63 \pm 0.46$ & $23.86 \pm 0.62$ \\
d1 & 55.30 & $20.21 \pm 0.41$ & $14.63 \pm 0.39$ & $15.11 \pm 0.57$ \\
e1 & 45.02 & $27.51 \pm 0.72$ & $16.32 \pm 0.53$ & $18.55 \pm 0.47$ \\
f1 & 34.10 & $32.15 \pm 0.81$ & $22.46 \pm 0.67$ & $24.50 \pm 0.55$ \\
\hline
\end{tabular}


NP is higher than the dispersion of the microparticles because NP have greater diffusion coefficient and mix quickly in the aerosol system. NP undergo numerous collisions with each other leading to agglomeration and growth; this mechanism is employed for the formation of NP. The mobility and concentration are two important factors, which influence the rate of agglomeration of NP [8].

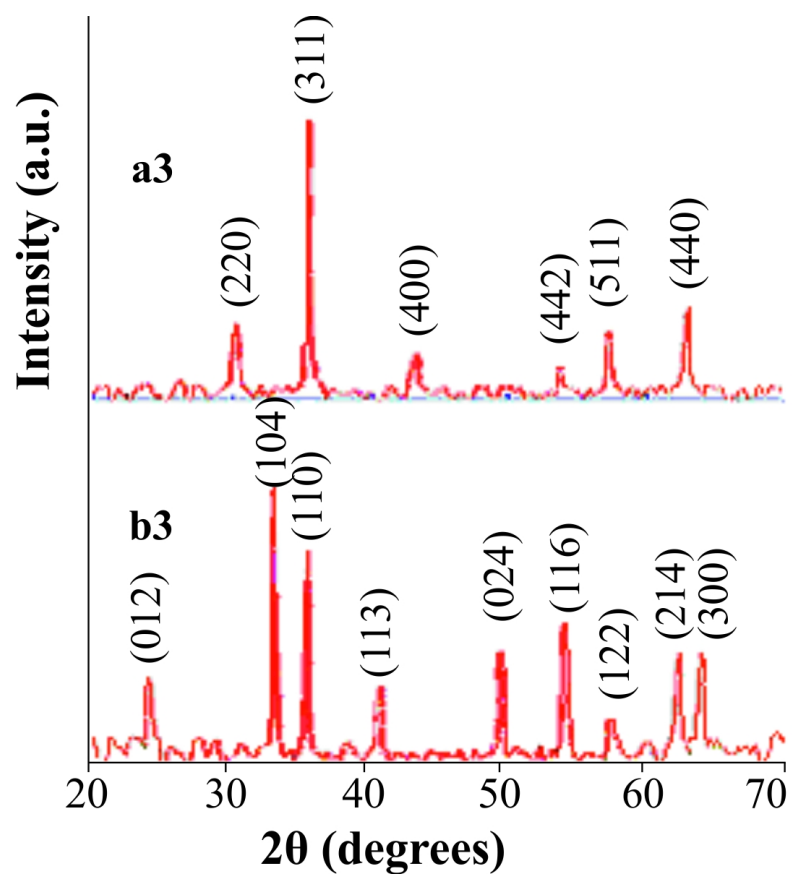

Fig. 6. XRD diffractograms of natural magnetite and its conversion directly to hematite at $600{ }^{\circ} \mathrm{C}$ via dry oxidation.

The natural magnetite particles larger than $200 \mathrm{~nm}$ directly transformed to hematite in the furnace, which is shown in Fig. 6. This process required higher temperature $\left(600{ }^{\circ} \mathrm{C}\right)$ and longer time (more than $2 \mathrm{~h}$ ), thus, showed higher resistance to oxidation. The formation of maghemite was bypassed in the oxidation process described in [17]. The Authors suggested that a little quantity of $\mathrm{OH}$ ions was available in the synthetic magnetite, which was necessary for maghemite formation. The $\mathrm{OH}$ ions were not available in the natural magnetite sample. The conversion of synthetic magnetite to maghemite at a temperature below $300{ }^{\circ} \mathrm{C}$ through dry oxidation was restricted by the outer layer of maghemite, which was produced at the beginning, thus, stopped the further transformation process at that temperature.

\section{Conclusions}

Synthetic magnetite nanoparticles were easily transformed into maghemite and hematite by dry oxidation process in air for $30 \mathrm{~min}$ and $60 \mathrm{~min}$ in the temperature range of 350 to $400{ }^{\circ} \mathrm{C}$ and 600 to $800{ }^{\circ} \mathrm{C}$, respectively. Natural magnetite particles larger than $200 \mathrm{~nm}$ were not transformed to maghemite but directly transformed to hematite. In dry state transformation, maghemite and hematite were dependent on the initial material used and retained the morphology of their precursor (magnetite). It was observed that the transformed particles had bigger size compared to magnetite particles.

\section{References}

[1] Xiangyuan L., Jun D., Jhon W., J. Mater. Res., 14 (1999), 3355.

[2] Jungk H.O., Feldmann C., J. Mater. Res., 15 (2000), 2244.

[3] Hsin-Yu L., YU-Wen C., Wi-Jye W., J. Nanopart. Res., 7 (2005), 249.

[4] Woo K., Hong J., Choi S., Lee H.W., Ahn J.P., KIM C.S., LEE S.W., Chem. Mater., 16 (2004), 2814.

[5] Yu-Lun C., Ming-Wei L., JiA-Qi L., Li-Jen C., Zhong L.W., Adv. Funct. Mater., 16 (2006), 2243.

[6] Xu Y.Y., Rui X. F., Fu Y.Y., Zhang H., Chem. Phys. Lett., 410 (2005), 36.

[7] Satyawati S.J., Prajakta R.P., Mashay S.N., BAKARE P.P., J. Nanopart. Res., 8 (2006), 635.

[8] Cornell R.M., Schwertmann U., The Iron Oxides: Structure, Properties, Reactions, Occurrences and Uses, Wiley-VCH, Weinheim, 2003.

[9] Montes-Hernandez G., Pironon J., Villieras F., J. Colloid Interf. Sci, 303 (2006), 472.

[10] Kazuhiko K., Noako O., Tatsuo I., Langmuir, 18 (2002), 2895.

[11] Majewski P., Maghemite, in: Encyclopaedia Britannica Online, http://search.eb.com/eb/ article-9049986, 2008.

[12] Thapa D., Palkar V.R., Kurup M.B., Malik S.K., Mater. Lett., 58 (2004), 2692.

[13] CORR S.A., GUN'Ko Y.K., Douvalis A.P., Venkatesan M., Gunning R.D., J. Mater. Chem., 14 (2004), 944.

[14] Chen T., Xu H., Xie Q., Chen J., Ji J., Lu H., Earth Planet Sc. Lett., 240 (2005), 790.

[15] Tang J., Myers M., Bosnick K.A., Brus L.E., J. Phys. Chem, 107 (2003), 7501. 
[16] Human Respiratory Tract Model for Radiological Protection. ICRP Publication 66, Ann. ICRP, 24 (1 - 3) (1994), 1.

Received 2014-04-24

[17] Sugimoto T., Adv. Colloid. Interfac., 28 (1987), 65.

Accepted 2014-12-23 